\title{
Patient Satisfaction Following Laparoscopic Umbilical Hernia Repair Using a "Two-Port" Technique
}

\author{
Ghassan Almaimani
}

\begin{abstract}
Background: Measuring patient satisfaction is important to help improve health service delivery and improve outcomes. The aim of this study is to evaluate patient satisfaction with laparoscopic umbilical hernia repair and determine overall satisfaction with referral, outpatient consultation, pre-assessment clinic attendance, and postoperative care.
\end{abstract}

Methods: This was a retrospective study of 52 patients undergoing laparoscopic umbilical hernia repair. Each patient completed an extensive self-administered questionnaire distributed at a scheduled follow-up appointment 3 months following the operation.

Results: The response rate was $86.5 \%$. Most patients $(77.8 \%)$ were referred from their general practitioner. Patient satisfaction with surgical outcome was very high at $>98 \%$, and the overall patient satisfaction from being listed for surgery to discharge was $>95 \%$ Patient satisfaction was significantly associated with the patient being referred to the hospital by a general practitioner (GP).

Conclusions: Patient satisfaction is an important health outconde, and understanding the domains of satisfaction, as well as therr relative importance to patients, is necessary to improve overall quality of patient care. Laparoscopic umbilical hernia repaie using a "two-port" technique is an effective procedure with excellentresults and an extremely high rate of patient satisfaction.

Keywords: Patient satisfaction Umbilical hernia; Ventral hernia; Laparoscopy

\section{Introduction}

Patient satisfaction is a subjective concept that is difficult to measure. Many factors are known to influence patient satisfaction, but it is unknown which areas of care actually influence overall satisfaction. Traditionally, clinical success has been measured by the absence of complications. More recent-

Manuscript submitted October 26, 2017, accepted December 15, 2017

Department of Surgery, Umm Al-Qura University, Alhijra Street, 21955 Makkah, Saudi Arabia. Email: dr.gaam@hotmail.com

doi: https://doi.org/10.14740/jcs333w ly, clinical outcomes have been assessed by patient-reported outcome measures (PROMs), where patient satisfaction is perhaps the most important criterion of success [1]. This concept is well recognized in the seprice industries but remains a nebulous concept in clinical eare. The two-port laparoscopic hernia repair technique is teponted to have the advantages of being the least minimally-jnvasive umbilical repair procedure described to date $[2,3]$. Here we build on our recent study of surgical ontcomes using the two-port laparoscopic hernia repair technigúe [4]. Although there have been several studies of patient outcomes after traditional hernia repair and laparoscopic repair using three- or four-port techniques, patient atisfaction after two-port umbilical hernia repair is unknown.

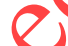

\section{Methods}

This was a retrospective study of 52 patients undergoing laparoscopic umbilical hernia repair at our hospital. Each patient completed an extensive self-administered questionnaire distributed at a scheduled follow-up appointment 3 months following the operation. Patients were surveyed on: 1) their referral route, 2) satisfaction with the surgical outpatient clinic service including any written information provided, 3) explanations provided before the preoperative assessment, and 4) satisfaction with surgical outcome. The care given to the patient before and after surgery was also assessed. All patients underwent hernia repair via the two-port technique. The Chisquared test was used to examine associations between variables and patient satisfaction. Data were analysed in Excel v17.7 (Microsoft Corp., Redmond, WA).

\section{Results}

Forty-five of 52 patients responded (86.5\%), with non-responding patients living abroad. Overall, $40 \%$ were male and $60 \%$ were female (Table 1$)$. The majority $(75 \%)$ of patients were 30 - 65 years old. Most patients $(77.8 \%)$ were referred by their general practitioner. Thirty $(66.7 \%)$ patients received their operation within 2 weeks of the surgical outpatient appointment.

Patient satisfaction with staff is shown in Figure 1. Overall, 43/45 (95.6\%) patients were satisfied with their care. Positive comments included praising the service and the friendly, sympathetic, and professional care given by doctors, nurses, 
Table 1. Patient Satisfaction Before, During, and After Laparoscopic Umbilical Hernia Repair

\begin{tabular}{|c|c|}
\hline & Number (\%) \\
\hline \multicolumn{2}{|l|}{ I. General questions } \\
\hline \multicolumn{2}{|l|}{ 1. Age groups } \\
\hline $30-40$ & $13(28.9 \%)$ \\
\hline $41-50$ & $9(20.0 \%)$ \\
\hline $51-60$ & $10(22.2 \%)$ \\
\hline $60-65$ & $13(28.9 \%)$ \\
\hline \multicolumn{2}{|l|}{ 2. Gender } \\
\hline Male & $18(40.0 \%)$ \\
\hline Female & $27(60.0 \%)$ \\
\hline \multicolumn{2}{|l|}{ 3. GP referral to clinic } \\
\hline \multicolumn{2}{|l|}{ 4. Self presentation } \\
\hline \multicolumn{2}{|l|}{ II. Questions related to visit our outpatient clinic } \\
\hline \multicolumn{2}{|l|}{ 1. Doctor introduced him/herself } \\
\hline \multicolumn{2}{|l|}{ 2. Patient felt doctor gave clear explanation } \\
\hline 3. Patient understood everything & $39(86.7 \%)$ \\
\hline 4. Patient invited to ask questions & $41(91.1 \%)$ \\
\hline 5. Patient given enough time to discuss everything & $39(86.7 \%)$ \\
\hline \multicolumn{2}{|l|}{ 6. Doctor discussed with patients } \\
\hline Benefits of surgery & $41(91.1 \%)$ \\
\hline Possible risks of surgery & $43(95.6 \%)$ \\
\hline Alternatives & $42(93.3 \%)$ \\
\hline Length of hospital stay & $38(84.4 \%)$ \\
\hline Patient felt doctor had provided all necessary information & $40(88.9 \%)$ \\
\hline \multicolumn{2}{|l|}{ III. Questions related to pre-assessment clinic } \\
\hline 1. Received the information sheet & $45(100 \%)$ \\
\hline 2. Patient read the information sheet & $33(73.3 \%)$ \\
\hline 3. Understood the information sheet & $30(66.7 \%)$ \\
\hline 4. Patient had no worries after reading theinformation sheet & $25(55.6 \%)$ \\
\hline 5. Meeting the anesthetist before the operation & $45(100 \%)$ \\
\hline \multicolumn{2}{|l|}{ IV. Questions related to operation, } \\
\hline 1. Patient reported no chronic pain & $45(100 \%)$ \\
\hline 2. Patient reported no clinical recurrence & $45(100 \%)$ \\
\hline 3. Patient satisfied with cosmetic outcome & $43(95.6 \%)$ \\
\hline \multicolumn{2}{|l|}{ V. Questions related to hospital stay after operation } \\
\hline 1. Patient satisfied with care provided & $43(95.6 \%)$ \\
\hline 2. Length of hospital stay was "right for me" & $44(97.8 \%)$ \\
\hline 3. Given information regarding self-care post-discharge & $45(100 \%)$ \\
\hline 4. Did not require analgesic once home & $38(84.4 \%)$ \\
\hline
\end{tabular}

and clerks. Forty-three $(43 / 45,95.6 \%)$ patients were satisfied with the aesthetic outcome and barely visible scars. Negative comments related to the waiting time in the outpatient clinic, which was up to $2 \mathrm{~h}$ for some patients.
The Chi-squared test was used to examine associations between age, gender, and general practitioner (GP) referral and patient satisfaction after surgery. There was no association between age or gender and patient satisfaction but patient 


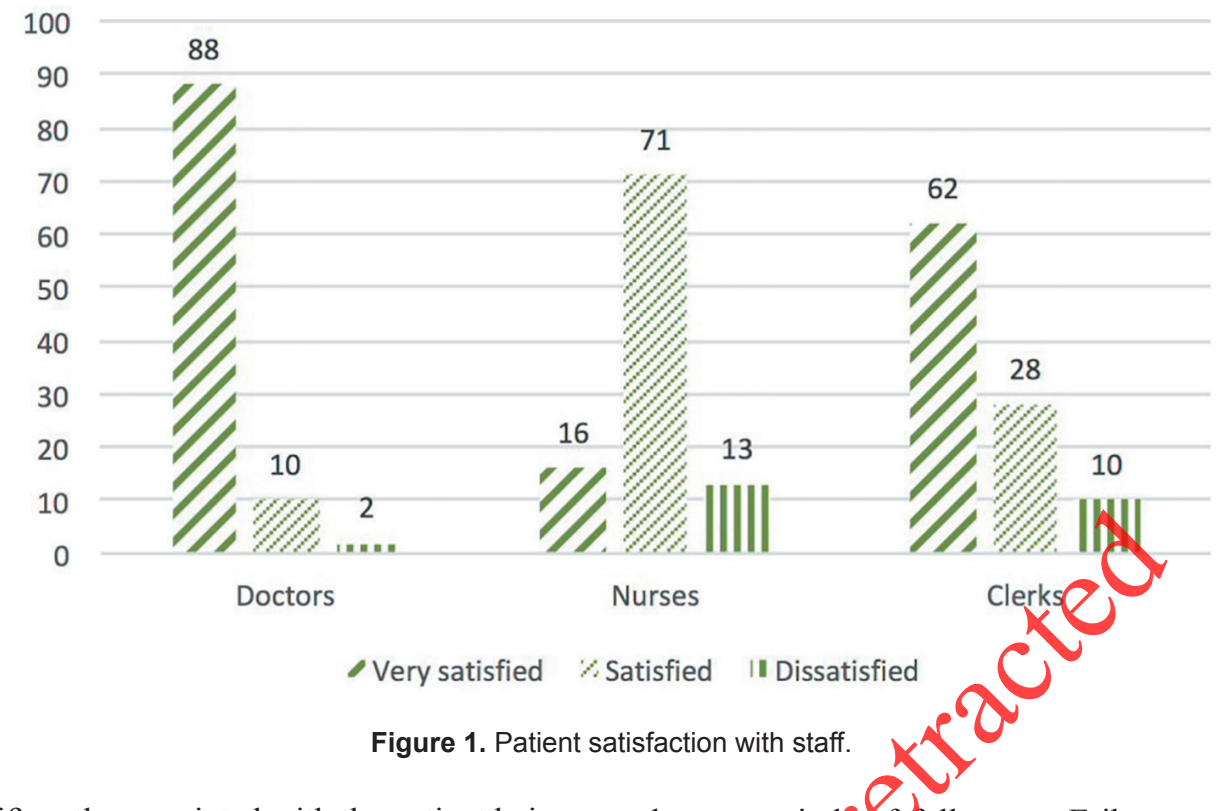

satisfaction was significantly associated with the patient being referred to the hospital by a GP.

\section{Discussion}

The ultimate goal of umbilical hernia repair is to improve and restore the patient's quality of life. This is achievable, especial ly when due emphasis is given to patient-reported outcomes. Patient-reported outcomes have become one of the most important measures for assessing medical and surgical treatments $[5,6]$.

Satisfaction represents a subjective assessment thather than an objective measurement [7]. Multiple factors can influence the assessment of satisfaction such as preoperative expectations, the way in which patients are handled by staff, the information provided to patients [8], and surgical outcome [9]. The timing of administration of satisfaction surveys may also influence how patients report satisfaction; many surveys are conducted soon after surgery or before hospital discharge, which may produce different findings from surveys conducted several days or weeks later [7]. For example, Lemos et al [9] surveyed patient satisfaction after ambulatory surgery at discharge and 30 days after surgery. Complete satisfaction was reported in $75 \%$ of patients at discharge, which decreased to $62 \%$ at 30 days. The authors postulated that patient satisfaction was strongly influenced by clinical outcome at the later time point.

Chronic pain and recurrence after laparoscopic umbilical hernia repair adversely affect satisfaction. In our study, patient satisfaction with surgical outcome was very high at $>98 \%$. Absence of chronic pain and recurrence and aesthetic outcome were the most important factors related to patient satisfaction after surgery in our study. Langbach et al [10] found that $60.5 \%$ of patients were satisfied even 10 years after laparoscopic ventral hernia repair, although a recurrence rate of $66.2 \%$ in that study could explain the relatively low satisfaction rates after longer periods of follow-up. Eriksen et al [11] reported that pain was assoeiated with dissatisfaction after laparoscopic ventral hernia repair in the absence of recurrences, while Liang efal [12] reported $74.6 \%$ satisfaction following laparoscopic) ventral hernia repair, with decreased patient satisfaction majnly associated with perception of poor cosmetic outcome and chronic pain.

As here, Wallin et al [13] reported that age and gender do not influence patient satisfaction after surgery. We found that the patient satisfaction was significantly increased when patients were referred to hospital by a GP. Guo et al [14] reported that patients need overall support from their doctor in order to be satisfied with treatment outcomes.

Comprehensive preoperative information causes little or no increase in overall patient anxiety [15]. Poor patient recall of verbal preoperative information is well documented [16, 17], and most respondents want written preoperative information. A standardized written information sheet may also be the best medium in which to mention rare complications, leaving time for the surgeon to verbally discuss patient-specific risks and postoperative expectations. In our study, patient satisfaction was significantly increased by giving them printed information.

This paper has some limitations. First, the survey was conducted 3 months after the operation, which may be too soon to assess optimal surgical outcomes or complications in terms of clinical recurrence. Second, the study population was relatively small. Finally, the satisfaction survey was a single question with "yes/no" responses, and this approach has been criticized as too simplistic to fully evaluate satisfaction [18].

\section{Conclusions}

Patient satisfaction is an important health outcome, and understanding the domains of satisfaction and their relative importance to patients is necessary to improve the overall quality 
of patient care. Laparoscopic umbilical hernia repair using a "two-port" technique is an effective procedure with excellent results and an extremely high rate of patient satisfaction.

\section{Acknowledgments}

We would like to thank all patients who participated in this study.

\section{Conflict of Interest}

The author declares no competing interests.

\section{Financial Support}

None.

\section{References}

1. Hamilton DF, Lane JV, Gaston P, et al. What determines patient satisfaction with surgery? A prospective cohort study of 4709 patients following total joint replacement. BMJ Open. 2013;3:e002525.

2. Abir F, Eisenberg D, Bell R. Laparoscopic ventral hernia repair using a two $(5-\mathrm{mm})$ port technique. JSLS. 2005;9(1):94-96.

3. Mehrotra PK, Ramachandran CS, Arora V. Two port laparoscopic ventral hernia mesh repair: an innovativetechnical advancement. Int J Surg. 2011;9(1):79-82.

4. Almaimani G, Oyais A. Laparoscopic umbilical hernia repair using a "two-port" technique: a single-center experience. J Curr Surg. 2017;7:39-41.

5. Turnbull JE, Luther KM. Patient satis aetion report paves way to improved care. QRC Adxis. 1996;13(1):1-7.

6. Wright JG. Evaluating the outcome of treatment. Shouldn't We be asking patients if they are better? J Clin Epidemiol. 2000;53(0):549-553.
7. Royse CF, Chung F, Newman S, Stygall J, Wilkinson DJ. Predictors of patient satisfaction with anaesthesia and surgery care: a cohort study using the Postoperative Quality of Recovery Scale. Eur J Anaesthesiol. 2013;30(3):106110 .

8. Caljouw MA, van Beuzekom M, Boer F. Patient's satisfaction with perioperative care: development, validation, and application of a questionnaire. Br J Anaesth. 2008;100(5):637-644.

9. Lemos P, Pinto A, Morais G, Pereira J, Loureiro R, Teixeira S, Nunes CS. Patient satisfaction following day surgery. J Clin Anesth. 2009;21(3):200-205.

10. Langbach O, Bukholm I, Benth JS, Rokke O. Long term recurrence, pain and patient satisfaction after ventral hernia mesh repair. World J Gastrointest Surg. 2015;7(12):384-393.

11. Eriksen JR, PoornoroozY $\mathrm{P}$, Jorgensen LN, Jacobsen B, Friis-Andersen HU, Rosenberg J. Pain, quality of life and recovery after laparoscopic ventral hernia repair. Hernia. 2009;13(1):13-21.0

12. Liang MK, CTappM, Li LT, Berger RL, Hicks SC, Awad S. Patient Satisfaction, chronic pain, and functional status following laparoscopic ventral hernia repair. World $\mathrm{J}$ Surg. 2013;37(3):530-537.

13. Wallin $\mathrm{E}$, Lundgren $\mathrm{P}$, Ulander K, Holstein C. Does age gender or educational background affect patients' satisfaction with short stay surgery? Ambulatory Surg. 2000;8:79-88.

14. Guo Y, Kuroki T, Yamashiro S, Koizumi S. Illness behaviour and patient satisfaction as correlates of self-referral in Japan. Fam Pract. 2002;19(4):326-332.

15. Newton-Howes PA, Bedford ND, Dobbs BR, Frizelle FA. Informed consent: what do patients want to know? $\mathrm{N} \mathrm{Z}$ Med J. 1998;111(1073):340-342.

16. Dawes P, Davison P. Informed consent: what do patients want to know? J Royal Soc Med. 1994;87:149-152.

17. Nisselle $\mathrm{P}$. Informed consent. $\mathrm{N} Z \mathrm{Z}$. 1993;106(961):331-332.

18. Chanthong P, Abrishami A, Wong J, Herrera F, Chung F. Systematic review of questionnaires measuring patient satisfaction in ambulatory anesthesia. Anesthesiology. 2009;110(5):1061-1067. 